\title{
INTERVENÇÃO COM \\ ADOLESCENTES POR \\ MEIO DE GRUPOS FOCAIS: \\ UMA ESTRATÉGIA DE \\ DEMOCRATIZAÇÃO ESCOLAR
}

\author{
INTERVENTION WITH \\ ADOLESCENTS THROUGH \\ FOCUS GROUPS: A STRATEGY \\ FOR A DEMOCRATIC SCHOOL
}

\section{RESUMO}

A presente intervenção é oriunda de uma disciplina de graduação do curso de Psicologia, que possui caráter extensionista e teve como objetivo auxiliar nas mudanças e nos desenvolvimentos socioemocionais de adolescentes, a partir de grupos focais cujos temas foram escolhidos pelos próprios alunos, a saber: Futuro profissional e família; cyberbullying; feminismo, religião e sexualidade. Na primeira etapa do estudo, participaram 104 adolescentes de uma escola no Pará. Destes, 26 se voluntariaram para integrar os grupos focais, a partir dos temas de seus interesses. Nesta etapa, os adolescentes tiveram a oportunidade de expor suas opiniões, bem como se posicionar frente a diversos assuntos de forma crítica e reflexiva. Destaca-se a importância do psicólogo escolar em propor e intermediar atividades que possibilitem debates e vivências, bem como agir neste processo como um profissional que possui uma visão ampliada, entendendo o indivíduo a partir de um contexto histórico e social.

Palavras-chave: Adolescência; Psicólogo escolar; Grupo focal; Desenvolvimento.

\section{ABSTRACT}

This study results from an outreach intervention carried out in a discipline of the undergraduate Psychology course. It was designed to help the changes and the social-emotional development of adolescents through focus groups. The themes were chosen by the ones that took part on the intervention and were related to their professional future and family, cyberbullying, feminism, religion and sexuality. The first stage was conducted among 104 adolescents from a school in Pará, Brazil. Twenty-six of those students volunteered to join focal groups in accordance with the subjects of their own interest. During this stage,

* Alunas de graduação da Universidade Federal do Pará (UFPA), PA - Brasil

** Professora da Universidade Federal do Pará (UFPA), PA - Brasil. E-mail: alinebcm@gmail.com 
the participants had the opportunity to express their opinions as well as to take a stand on themselves, critically and reflectively, about several subjects. It is relevant to highlight the importance of school psychologist to suggest and intermediate activities that stimulate participants to share and discuss their experiences as well as to act as the one who understands the person from a historical and social context.

Keywords: Adolescence; School psychologist; Focus group; Development.

\section{Introduçáo}

Historicamente, a atuação do psicólogo no contexto escolar esteve centralizada no estabelecimento do diagnóstico, atendimento, orientação e intervenção, principalmente em relação a problemas de aprendizagem e de comportamento (MARTINEZ, 2010). Essa visáo tradicional de abordar os problemas dentro do contexto escolar ainda prevalece em muitas instituições, através de posturas generalistas, não considerando as individualidades dos alunos.

Nos últimos anos, vem surgindo um novo modelo de atuação do psicólogo escolar, em que o indivíduo é considerado parte de sistemas relacionais constituídos cultural e historicamente (MARTINEZ, 2010). Esses indivíduos influenciam e são influenciados pelo contexto social no qual estão inseridos, por isso a dinâmica escolar terá um impacto no desenvolvimento e na subjetividade deles.

Assim, o psicólogo escolar deve possuir um olhar amplificado sobre a instituição a qual pertence, com um olhar de pesquisador, observando, analisando, avaliando e escrevendo novas possibilidades de atuação (ANDRADA, 2005).

Dessa forma, sua atuação deve estar voltada à compreensão dos processos relacionais ocorridos na instituição, na qual trabalham com o público adolescente, procurando conhecer os modos pelos quais os alunos sentem, pensam e atuam nesse espaço.

Entende-se esse período da adolescência como um momento cheio de nuances, pois segundo Papalia, Olds e Feldman (2006), as transformaçóes físicas visíveis deste período também influenciam as mudanças nos sentimentos destes jovens. Assim, segundo os autores, a maturidade emocional dos adolescentes depende de fatores como realizaçóes, descobrimento da identidade, independência dos pais, desenvolver seu sistema de valores e formar relacionamentos.

O início da adolescência é quando ocorre a transição entre a saída da infância e a entrada na vida de jovem. Esse momento oferece chances de crescimento físico, cognitivo e social, a partir do desenvolvimento da autonomia, autoestima e intimidade. (PAPALIA et al., 2006).

Entende-se o período da adolescência como um momento crítico do desenvolvimento de qualquer ser humano, pois se caracteriza como uma fase onde este indivíduo está descobrindo sua própria identidade, ou seja, a primeira barreira desenvolvimental por ele enfrentada (ERIKSON,1963 apud SHAFFER, 2005). Erikson fala em "crise de identidade" para se referir à confusão e ansiedade que os adolescentes podem apresentar ao pensarem em quem, realmente, são e quem poderão se tornar. Ao mesmo tempo, são bombardeados por uma infinidade de informações e cobranças, já que, conforme vão se tornando mais velhos, as responsabilidades sociais esperadas aumentam de forma brusca.

Concomitantemente, é comum que os adolescentes se sintam inseguros em relação a várias questóes, principalmente à descoberta de sua sexualidade e como pretendem vivenciá-la. Além disso, espera-se que os mesmos tenham a maturidade para tomar decisóes de extrema importância, como a carreira que pretendem seguir no futuro. Com isso, é comum que adolescentes apresentem dificuldades em lidar com muitas mudanças ao mesmo tempo, e de acordo com Papalia et al. (2006), essas mudanças podem demandar necessidade de auxílio para superar os perigos ao longo do caminho e, muitas vezes, 
o suporte oferecido a esse grupo é insuficiente, não só no que diz respeito ao papel da família, mas também ao papel da escola.

A partir dessa visão da adolescência como um período de transição e por vezes conturbado, foi realizado um trabalho com adolescentes entre 15 e 18 anos, estudantes do segundo ano do Ensino Médio de uma escola situada na cidade de Belém do Pará. O trabalho desenvolvido é parte de uma disciplina do Curso de Graduação de Psicologia, denominada "Estágio Básico IV - Psicologia Escolar", que possui por definição caráter extensionista. Como definido pelo Fórum de Pró-reitores de Extensão - FOPROEX (2012, p. 16), no Plano Nacional de Extensão Universitária:

Extensão Universitária denota também prática acadêmica, a ser desenvolvida, como manda a Constituição de 1988, de forma indissociável com o Ensino e a Pesquisa, com vistas à promoção e garantia dos valores democráticos, da equidade e do desenvolvimento da sociedade em suas dimensóes humana, ética, econômica, cultural, social. (p.16)

Desta forma, a referida disciplina propóe como método de ensino a atuação supervisionada da equipe de estágio na Escola de Aplicação da Universidade, com o objetivo de desenvolver práticas que favoreçam a promoçáo dos valores democráticos e o desenvolvimento humano, ético, cultural e social da população com que são desenvolvidas as açóes.

No caso do presente relato, o objetivo foi auxiliar o desenvolvimento socioemocional adolescente, através da discussão de diversas temáticas escolhidas pelos próprios participantes. Foi almejado, assim, ouvir a voz desses indivíduos a respeito dos assuntos que consideram como suas demandas, dando suporte à equipe na promoçáo de debates acerca desses temas. Essas discussóes oportunizaram compreender a posição do alunado em relação aos aspectos debatidos, como também a possibilidade de ampliar o olhar e a consciência desses sujeitos ao apresentarmos a eles diferentes formas de abordar o mesmo conteúdo.

Essas conversas foram realizadas mediante grupos focais, por se entender que este instrumento, segundo Lopes (2014), possibilita compreender como se dá a construçáo da realidade vivenciada pelos alunos, a partir de suas práticas cotidianas, tanto aquelas observadas pela equipe do projeto em observaçóes na sala de aula, quanto as relatadas pelos alunos durante conversas com os mesmos, ou ainda entre conversas com seus colegas. Através deste instrumento, pode-se perceber atitudes e comportamentos comuns entre si, os quais seriam relevantes para o objetivo proposto (LOPES, 2014), bem como promover a reflexão sobre as temáticas discutidas.

Este instrumento possibilita lidar com uma intervenção grupal (SERVO; ARAUJO, 2012), dado o número de pessoas que se interessaram em participar das discussóes, e, ainda segundo as autoras, é uma forma de lidar com dimensóes subjetivas. A estratégia objetiva é construir um espaço em que seja possível explicitar as dificuldades que possam estar cristalizadas ao longo da vida, neste caso, no decorrer mais especificamente do período da adolescência.

De acordo com o CFP, na Resolução no 014/00 (apud ANDRADA, 2005), uma das tantas atuações do psicólogo é:

Aplicar conhecimentos psicológicos na escola, concernentes ao processo ensino-aprendizagem, em análises e intervençôes psicopedagógicas; referentes 
ao desenvolvimento humano, às relaçóes interpessoais e à integração famíliacomunidade-escola, para promover o desenvolvimento integral do ser.

A partir dessas atribuições do Conselho de Psicologia, foi realizada a intervenção, para possibilitar o desenvolvimento humano dos alunos, a partir da melhora das relaçóes interpessoais e, principalmente, a promoção do desenvolvimento social e psicológico daquele grupo.

\section{Método}

A intervenção aqui relatada pode ser dividida em três etapas. A primeira etapa foi de observação participante em sala de aula e a segunda a aplicação de questionário. A terceira etapa consistiu na realização de grupos focais. $\mathrm{O}$ presente relato será com base na experiência vivenciada a partir da terceira etapa.

\section{Participantes}

A atividade abrangeu 104 estudantes de ambos os sexos, regularmente matriculados no segundo ano do Ensino Médio de uma escola situada na cidade de Belém do Pará. Os alunos tinham entre 15 e 18 anos. Na terceira etapa da intervençáo, participaram 26 alunos, pertencentes ao grupo inicial, que se inscreveram voluntariamente para discutir os temas propostos.

Não houve procedimento de amostragem, pois se objetivava oportunizar a participaçáo de todos os interessados. Assim, nas duas primeiras etapas, foi envolvido todo o universo de alunos do segundo ano do Ensino Médio. A terceira etapa contou com um contingente reduzido, em função de valorizar a autonomia discente para aderir ou náo à proposta e para escolher o tema que teria interesse em debater.

\section{Ambiente}

Todas as atividades foram realizadas nas dependências de uma Escola de Aplicação Federal, em salas de aula disponibilizadas à nossa equipe.

\section{Materiais e Instrumentos}

Os instrumentos utilizados para a realização das atividades foram questionários desenvolvidos especificamente para esta intervençáo, após a observaçáo das turmas, com o objetivo de levantar as opinióes dos alunos sobre a estrutura física da escola e o funcionamento da equipe pedagógica, além de interesses pessoais (como gosto musical, atividades no tempo livre e assuntos que gostariam de discutir).

Nos grupos focais, foram utilizados recursos audiovisuais para reproduçáo do vídeo "Coisinhas Flutuantes", retirado da plataforma de vídeos online Youtube. 


\section{Procedimento}

A intervenção iniciou-se com as cinco estagiárias divididas nas cinco turmas de segundo ano do Ensino Médio existentes na instituição, iniciando a primeira etapa com a observação-participante. As estagiárias permaneceram nas salas de aula durante três horas, por três dias. Nesse período, as integrantes da equipe ficaram alocadas em sua respectiva sala, buscando conhecer o cotidiano dos alunos para, entáo, programar as etapas seguintes da intervenção.

Após a observação-participante, houve a segunda etapa de aplicação de questionário. Este questionário buscou identificar o perfil discente, procurando conhecer os interesses dos alunos e os assuntos representativos como demanda para este grupo. Antes da aplicação do questionário, cada estagiária explicou a respeito do sigilo das informaçóes nele contidas, assim como o objetivo do instrumento. No início, havia campos para o nome do aluno, com a informação de que a identificaçáo não era obrigatória, bem como campos para o preenchimento da idade do aluno e sua turma.

Os dados obtidos por meio dos questionários possibilitaram perceber quais assuntos eram relevantes para os alunos, assim como quais alunos gostariam de participar espontaneamente dos grupos focais. Foi feita uma inscrição voluntária em todas as turmas de participantes da intervençáo com a lista de cada grupo focal, e, posteriormente, todos os inscritos nos grupos foram lembrados da data e do horário em que iriam acontecer, para que a participaçáo fosse mais efetiva. Cada grupo focal teve duraçáo de $1 \mathrm{~h} 30 \mathrm{~min}$, com duas a três estagiárias em cada grupo, sendo realizados três grupos durante dois dias.

A condução dos grupos focais era feita considerando três momentos: 1) Abertura da interação pelas mediadoras, provocando reflexóes iniciais; 2) A fala livre dos participantes, com reflexóes propostas pelas mediadoras; e 3) $\mathrm{O}$ fechamento com encontro, com uma síntese pelas mediadoras e a avaliação da experiência por parte dos participantes.

Os temas foram distribuídos da seguinte forma:

Grupo 1 - Cyberbullying

Grupo 2 - Futuro profissional e família

Grupo 3-Sexualidade, feminismo e religião nas escolas.

\section{Resultados}

Descrição breve de cada grupo focal realizado, mencionando as questóes discutidas durante a dinâmica - incluindo aquelas que foram planejadas pela equipe e os tópicos que os adolescentes trouxeram de forma espontânea para o grupo. Para tal, foram utilizadas falas dos próprios participantes para ilustrar as diferentes opinióes que surgiram no debate.

\section{Futuro profissional e família}

Participaram do grupo 3 pessoas do sexo feminino. Como seriam abordados dois temas conjuntamente, foi separada a primeira metade do tempo para a discussáo de um tema e o outro tópico discutido no tempo restante. O tema inicial foi o futuro profissional e, para isso, foi utilizado recurso audiovisual para exibir o vídeo "Coisinhas flutuantes". Neste vídeo, a personagem fala sobre seu futuro profissional e as dúvidas que teve ao longo da vida, ao tentar decidir o que fazer. 
A partir disto, foi perguntado se elas se identificaram com o que havia sido falado no vídeo. Todas as participantes afirmaram que sim, utilizando palavras enfáticas como "completamente". Então, começaram a falar o porquê da identificação. O relato das participantes foi de que se sentiam bastante pressionadas a escolher uma profissão, no entanto, a pressão pessoal era muito maior do que a externa sobre essa escolha. As participantes falaram que os pais náo as pressionavam tanto, mas elas se pressionavam mais.

Outro aspecto destacado foi que, ao escolher a profissão, elas consideravam principalmente quais atividades eram mais prazerosas para elas e em quais teriam mais habilidades para desenvolver o trabalho requerido. Uma participante citou que tinha escolhido um curso para o vestibular, mas percebeu que não tinha domínio sobre uma matéria essencial para ele; com isso, ela passou a procurar outros cursos em que pudesse aplicar a habilidade que tinha e considerava possuir um bom desempenho.

Apesar de o retorno financeiro ser um fator considerado, disseram que isso não era o mais importante e, sim, fazer o que elas gostam. Outro aspecto discutido foi que, caso percebessem que o curso escolhido não era a opçáo mais adequada, elas estariam dispostas a mudar de curso. Contudo, consideraram que uma mudança deste tipo seria difícil e que percebiam que falar sobre esta disposição, naquele momento, era mais fácil do que a tomada de decisão durante o curso - sendo este um fator relevante para que a escolha fosse cuidadosa.

Chegada a metade do tempo disponível, as meninas terminaram de falar sobre o cuidado com a escolha da profissão, e, então, foi introduzido o próximo tema. Para começar a discussão sobre família, as participantes foram questionadas acerca da forma como definiam a palavra família. Uma delas respondeu que família era mais do que laço sanguíneo, com o que as demais concordaram. Após isso, passaram a descrever suas relações com seus familiares.

Em um primeiro momento, todas falaram que a relação entre elas e a família era boa, no entanto, no decorrer da conversa, surgiram inquietaçóes. Uma das participantes relatou um forte desejo em obter sua independência, já que não gostava de lidar com certos comportamentos dos pais, como a imposição de sua religiáo e a cobrança de determinadas atitudes e pensamentos.

Em outro momento, elas relataram sentir falta de uma relaçáo de amizade com os pais, construída de forma natural, desde o início de suas vidas, e não algo forçado em um momento que já seriam adolescentes. Algumas conversas ainda eram um tabu na relação familiar e elas não se sentiam à vontade para abordar certos assuntos com os pais, de modo que, nesses momentos, procuram os amigos. Durante o diálogo entre elas, foram feitas poucas intervençóes, pois a ideia era justamente que elas pudessem se sentir livres para falar.

Ao término do tempo, feito o fechamento do grupo, agradecendo a participação e realizada a pergunta se gostaram e como se sentiram. Elas disseram que tinham gostado muito do espaço e se sentiram à vontade para falar. Enfatizaram que, geralmente, ocorrem palestras e nelas elas náo se sentem à vontade. Apesar de o grupo ter sido pequeno e elas terem ficado nervosas no início, descreveram que, no decorrer da conversa, foram se sentindo mais relaxadas e gostariam que houvesse esse tipo de intervenção mais vezes na escola. Relataram, ainda, a vontade de que a área da psicologia fosse mais presente em seu cotidiano escolar. 


\section{Cyberbullying}

O grupo focal sobre cyberbullying teve cinco participantes, sendo três mulheres e dois homens. Inicialmente, a conversa teve como foco o que eles entendiam sobre cyberbullying. Eles usaram frases como "um bullying praticado na internet" e "falar mal ou fazer montagens de alguém no facebook" para conceituar o tema e foi possível perceber que havia um bom entendimento dos alunos sobre o que o termo designa.

Em seguida, foi lançada a pergunta se eles já haviam presenciado algum caso de cyberbullying, ao que relataram histórias de outros alunos da instituição que já haviam sofrido esse tipo de violência, ao serem alvo de compartilhamento de vídeos ou fotos íntimas, através de mensagens no celular. Uma aluna contou sua experiência pessoal de ter sido ridicularizada em uma rede social, por causa de uma foto.

Após ouvir o relato dos alunos, foi feita a leitura de algumas histórias reais de pessoas que haviam sido alvo de cyberbullying; pedimos para que falassem sobre como isso pode afetar a vida de quem sofreu esse tipo de violência. Diante dos relatos, os alunos questionaram seus próprios atos ao compartilharem conteúdos que expóem e ridicularizam as pessoas, e o grupo chegou à conclusão de que repassar esse tipo de conteúdo é praticar e ser conivente com esse tipo de crime.

Outra questão norteadora do grupo foi sobre as motivaçóes da prática de crimes virtuais, e o grupo chegou ao consenso de que isso era decorrente da possibilidade de anonimato e consequente sensação de impunidade que o cyberbullying gera. A partir disso, o debate voltou-se para o esclarecimento de algumas leis que existem para combater esse tipo de crime, e um dos alunos falou sobre a existência da Delegacia de Crimes Virtuais, demonstrando seu conhecimento, e, a partir da oportunidade criada pelo grupo focal, compartilhando-o com o grupo de pares.

Outro ponto importante foi o relato dos alunos sobre a necessidade de a instituição de ensino tratar o cyberbullying com seriedade, buscando maneiras de combater e punir esse tipo de prática.

As mediadoras do grupo finalizaram o debate fazendo uma síntese de tudo o que havia sido discutido e enfatizando algumas conclusóes que o grupo havia elaborado em conjunto. Ficou claro que cyberbulying é um tema muito presente entre os alunos, devido à imersão neste meio de redes sociais e conversas on line. Eles relataram a importância de se discutir esse tema entre eles, o que possibilitou muitos esclarecimentos e novas formas de entender a complexidade de tal violência.

A partir da exposição do tema e dos relatos, foi possível perceber que houve maior sensibilização dos alunos em relação às pessoas que são vítimas deste tipo de bullying. Eles perceberam que, às vezes, perpetuam o cyberbullying, e elencaram maneiras de combatê-lo, após compreender que náo se trata de algo banal ou uma brincadeira entre os usuários de redes sociais, mas, sim, de um crime que gera grande sofrimento emocional nas vítimas.

\section{Feminismo, sexualidade e religiáo}

Participaram do grupo 18 estudantes, sendo 6 meninos e 12 meninas. Durante o grupo focal, iniciamos questionando os alunos a respeito da forma como definiam e o que entendiam por sexualidade. Devido ao número grande de participantes, as respostas foram bastante variadas e incluíam aspectos relacionados a Doenças Sexualmente Transmissíveis 
- DSTs, ao ato sexual, à orientação sexual e à necessidade de se falar sobre esses temas com a família e com a escola.

De acordo com os adolescentes, embora a escola promova discussóes acerca de sexualidade, elas são focadas no aspecto biológico. Eles afirmam sentir a necessidade de haver discussóes voltadas para métodos contraceptivos e questóes subjetivas relativas ao sexo e gravidez na adolescência.

Em relação à gravidez na adolescência e ao momento adequado para dar início à vida sexual, uma participante afirmou que o sexo deve ser evitado até que o sujeito esteja casado formalmente, pois, segundo ela, os jovens, em sua grande maioria, não possuem maturidade para ter uma vida sexual de forma responsável, o que aumentaria as chances de uma gravidez indesejada, e essa gravidez acarretaria sérias consequências, vista pela aluna como catastrófica.

No entanto, outros alunos questionaram tal posicionamento e debateram a respeito das consequências, além de defenderem o início da vida sexual no momento em que a pessoa se sentir preparada, e sobre a utilizaçáo de métodos contraceptivos para evitar a gravidez indesejada.

A partir desta fala, foi discutido como geralmente apenas a mulher é culpabilizada pela gravidez indesejada, já que, segundo eles, a responsabilidade de se proteger contra a gravidez e, posteriormente, cuidar da criança é socialmente atribuída ao gênero feminino. A seguinte fala ilustra essa perspectiva:

\section{"A mulher que tem que tomar anticoncepcional, a culpa é só da mulher".}

Em seguida, o grupo começou a debater sobre religiáo. Algumas pessoas falaram qual religião praticavam e as suas características variadas. Outros disseram não ter uma religiấo ou não a frequentarem assiduamente. Um ponto importante tocado foi em relação à religiáo na escola. Eles disseram que a escola, apesar de não ser religiosa, primava por uma religiáo, enquanto criava barreiras para a promoçáo de outras.

Outro tópico comentado em relação à religião foi como a virgindade era vista, de acordo com as religióes. Um ponto destacado foi o fato de algumas religióes dizerem que o sexo deveria ser feito apenas depois do casamento. Os adolescentes debateram sobre isso e as opinióes foram diversas - tanto a favor quanto contra esse tipo de posição.

Como o grupo começou a desviar do tema central para outras questóes, as mediadoras retomaram a temática a partir do questionamento acerca dos papéis que eles exerciam na sociedade e se percebiam alguma diferença entre ser mulher e ser homem. A partir disso, foi discutido o tema feminismo e a questáo dos papéis sociais e diferenças de gênero. De forma geral, as adolescentes mulheres que participaram do grupo afirmavam que havia uma grande diferença na forma como os homens e mulheres são encorajados socialmente a vivenciarem a sua sexualidade - o que foi concordado por alguns participantes do sexo masculino.

Segundo elas, o homem é incentivado a vivenciar a sua sexualidade de forma exacerbada, enquanto as mulheres são reprimidas e incentivadas a não se sentirem livres para vivenciar a sexualidade da forma que desejam.

As jovens afirmaram que consideram a sociedade em que vivem "bastante machista" e que não acham corretas as imposiçóes sociais sobre as mulheres. Elas acreditam que deveriam ter o direito de "conduzir suas vidas sexuais da forma que quisessem" e, por 
isso, creem na importância do feminismo. Segundo elas, o movimento feminista ajuda a promover a liberdade das mulheres.

Em seguida, a maioria das meninas do grupo começou a falar sobre assédios que acontecem em diversos ambientes, como nas ruas, transportes públicos e até mesmo dentro da escola. Elas relataram diversos abusos que já sofreram, e, ao conversarem sobre isso, houve uma grande comoção. Algumas disseram que náo tinham espaço para falar sobre o assunto em foco e que é muito bom e importante haver lugares em que elas se possam se sentir confiantes em desabafar. Elas comentaram sobre o medo e a insegurança em relação a esses casos e pediram para que os meninos não reproduzissem tal tipo de violência. $\mathrm{O}$ grupo, como um todo, ficou bastante sensibilizado.

Foi promovida uma reflexão no grupo, mudando a forma de ver situaçóes que eram naturalizadas como brincadeiras, para uma nova percepção de que essas atitudes são uma forma de violência e causam enorme sofrimento para as vítimas. Alguns dos meninos que participavam do grupo afirmaram que, no passado, por várias vezes, haviam cometido algum tipo dos assédios mencionados pelas adolescentes, e que a partir daquele momento evitariam cometer os atos novamente. $\mathrm{O}$ momento muito significativo da intervenção, por demonstrar o potencial transformador do tipo de atividade desenvolvida.

Realizamos o fechamento do grupo focal pedindo aos participantes que avaliassem a dinâmica realizada e, de forma geral, o grupo afirmou considerar esse tipo de atividade muito proveitosa, já que é raramente promovida dentro do ambiente escolar, além de suprir a sua demanda - a de possuir um espaço em que podem expressar suas opinióes.

\section{Discussáo}

A partir dos dados coletados, tanto nos questionários quanto nos grupos focais, foi possível entrar em contato com a crise de identidade característica da adolescência (ERIKSON, 1963 apud SHAFFER, 2005). Para Erikson, esta crise pode estar relacionada à influência de diferentes meios de informaçáo, como a igreja, os pais, a escola, os amigos, os meios de comunicação e as redes sociais - que, por muitas vezes, podem ser conflitantes entre si. Um exemplo desse conflito foi observado durante o Grupo Focal 3, no qual participantes relataram dúvidas sobre o momento adequado para o início da vida sexual, pois a igreja defende a relaçáo sexual somente dentro do casamento, enquanto os amigos defendem a liberdade sexual independente do casamento.

Os relatos obtidos por meio dos grupos focais corroboram, ainda, a necessidade de auxílio e a insuficiência de suporte oferecida aos adolescentes, já que muitos deles, em diferentes grupos, relataram a dificuldade que possuíam de conversar com seus pais sobre determinados assuntos (como sexualidade, uma vez que era considerado um tabu debater este tema), assim como na escola, que apesar de discutirem esse assunto, o enfoque foi descrito como sendo sob o aspecto biológico (como as DST's e métodos contraceptivos), enquanto os aspectos subjetivos e emocionais (como qual o melhor momento para o início da vida sexual) eram ignorados.

Assim, esses grupos focais confirmam a necessidade de um espaço para discussão, onde a sua opinião seja considerada como relevante, bem como façam parte da construção desses debates de maneira espontânea. Pôde-se perceber que o papel de mediaçáo proposto pelo grupo, provendo questôes norteadoras apenas, foi suficiente para permitir que os 
participantes contribuíssem uns com os outros na construção de um pensamento crítico e reflexivo sobre os temas propostos.

Acredita-se, assim, que a construção de espaços de diálogo no contexto escolar, tal qual realizado nesta experiência, pode ser uma ferramenta eficaz na democratização do ensino e para o empoderamento do adolescente sobre seu próprio processo de amadurecimento (como propóe o Conselho Federal de Psicologia, 2013).

Nos três grupos focais realizados, surgiram demandas em comum que valem a pena serem destacadas, como a necessidade de haver um espaço em que os alunos tenham a oportunidade de expor suas opiniōes, e não somente palestras em que apenas recebam informaçóes, sem se posicionarem efetivamente.

Segundo o relatório da Unesco (2010), existem quatro pilares da educaçáo: aprender a conhecer, aprender a fazer, aprender a conviver e aprender a ser. A escola prioriza o conhecer e o fazer, que seriam voltados para o conhecimento técnico para desenvolver e adquirir uma profissão, uma aprendizagem voltada às exigências do mercado de trabalho. É necessário que a educação também leve em consideração o conviver e o ser, em que a aprendizagem seja baseada no respeito às pluralidades e em responsabilidade social, promovendo discussóes e reflexóes que tornem possível o desenvolvimento de alunos comprometidos com as diferenças culturais e sociais presentes na sociedade.

As açóes realizadas por nossa equipe colaboram para esses objetivos, pois os grupos focais realizados deram a oportunidade para os alunos exporem suas opinióes, e até mesmo relatarem sobre possíveis preconceitos que enfrentam em seus cotidianos. Ao compartilharem suas experiências com o grupo, foi possível que os outros se sensibilizassem com o sofrimento de seus colegas.

Dessa forma, os adolescentes puderam perceber a existência de dificuldades que determinados grupos enfrentam, mesmo que eles próprios não estivessem inseridos naquele grupo, colaborando para que esses jovens se tornem mais empáticos e conscientes, capazes de desenvolver um senso crítico que irá ajudá-los a não perpetuar diferentes tipos de preconceito, como também incentivá-los a combater os mesmos.

\section{Conclusão}

Consideramos nossa intervenção importante, pois ela está de acordo com o novo modelo de atuação do psicólogo escolar definido por Martinez (2010), que considera que o olhar do psicólogo deve ser ampliado, percebendo-se os indivíduos dentro de um contexto social e histórico.

Neste sentido, Andrada (2005) afirma que este olhar amplificado do profissional traz novas possibilidades de atuação, de modo que a intervenção aqui relatada se configura como um exemplo dessas novas possibilidades.

$\mathrm{Na}$ presente experiência de extensão, foram identificadas demandas a respeito de temas específicos, possibilitando ser desenvolvida uma nova possibilidade de atuação, discutindo tais temas (cyberbullying, futuro profissional, família, sexualidade, feminismo e religiáo) na escola. Essa maneira de atuar na escola pode ser considerada inovadora no contexto em que foi aplicada, dado que os alunos nunca haviam se reunido para refletir acerca de assuntos decididos por eles, sob orientação de um psicólogo. 
Assim, pôde-se sair do paradigma que tantos psicólogos escolares acabam embarcando, de acordo com Andrada (2005), em separar os alunos entre normais e desviantes, propondo intervençóes apenas direcionadas àqueles inseridos na categoria "desviante". Considera-se, assim, que a ausência de critérios para seleção de alunos participantes dos grupos oportunizou a se expressar qualquer aluno que estivesse interessado em participar.

Há diversos problemas enfrentados pelos psicólogos escolares, seja pelos paradigmas citados, seja pela enorme demanda apresentada na escola, dificultando a atuaçáo deste profissional; ou mesmo por não haver uma prática específica elaborada de sua atuaçáo, pelo fato de não existirem teorias capazes de refletir a realidade da escola pública no Brasil, necessitando de uma intervenção psicológica diferenciada (ANDRADA, 2005).

Compreendemos que o nosso trabalho possui importância neste cenário, por apresentar possíveis estratégias de intervenção, de caráter tanto preventivo quanto remediativo, compatíveis com o contexto de uma escola pública.

A necessidade de açóes do tipo aqui apresentado ficou clara nas falas dos alunos em todos os grupos, onde foi relatada a escassez das referidas práticas, além da falta de diálogo entre o setor de psicologia e os estudantes. Portanto, acreditamos na importância de que a escola não foque apenas na educação formal, mas preocupe-se com o desenvolvimento social, emocional e psicológico dos alunos, promovendo debates a partir das demandas identificadas pelos próprios alunos, para que eles se tornem ativos nesse processo.

\section{Referências}

ANDRADA, E. G. C. Novos Paradigmas na Prática do Psicólogo Escolar. Psicologia: Reflexão e Crítica, Porto Alegre, v.18, n.2, p. 196-199, 2005.

EDUCAÇÃO: UM TESOURO A DESCOBRIR (1996). Relatório para a Unesco da Comissão Internacional sobre Educação para o século XXI. Relatório. Brasília: UNESCO, 2010.

FÓRUM DE PRÓ-REITORES DE EXTENSÃO DAS UNIVERSIDADES PÚBLICAS BRASILEIRASFORPROEX. Política Nacional de Extensão Universitária. Manaus: Ed. UFMG, 2012.

JOUT JOUT PRAZER. Coisinhas Flutuantes. Disponível em: <https://www.youtube.com/ watch?v=CC1 rbEMtOCk >. Acesso em: 5 nov. 2015.

LOPES, B. E. M. Grupo focal na Pesquisa em Ciências Sociais e Humanas. Revista Educação e Políticas em Debate, v.3, n.2, 2014.

MARTINEZ, M. A. O que pode fazer o psicólogo na escola? Em aberto, Brasília, v.23, n. 83, p. 39-56, 2010.

PAPALIA, D. E.; OLDS, S. W.; FELDMAN, R.; D. Desenvolvimento Humano. 8. ed. Porto Alegre: Artmed, 2006. 
SERVO, M. S.; ARAÚJO, P. O. Grupo Focal em Pesquisas Sociais. Revista espaço acadêmico, v.12, n.137, 2012.

SHAFFER, D. R. Psicologia do desenvolvimento - Infância e adolescência. 5. ed. São Paulo: Thomson, 2005. 